\title{
Publisher Correction: Exploring the bottlenecks of anionic redox in Li-rich layered sulfides
}

Sujoy Saha, Gaurav Assat (D), Moulay Tahar Sougrati (D), Dominique Foix, Haifeng Li, Jean Vergnet (D), Soma Turi,

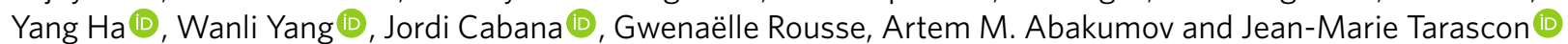

Correction to: Nature Energy https://doi.org/10.1038/s41560-019-0493-0, published online 14 November 2019.

In the version of this Article originally published, the tickmarks on the $x$ axis in Fig. 5e were labelled incorrectly; the values shown were $160,164,168$ and $172 \mathrm{eV}$, but they should have been 162, 167 and $172 \mathrm{eV}$ and on the major tickmarks only. The corrected Fig. 5e is shown below and has been updated in all versions of the Article.
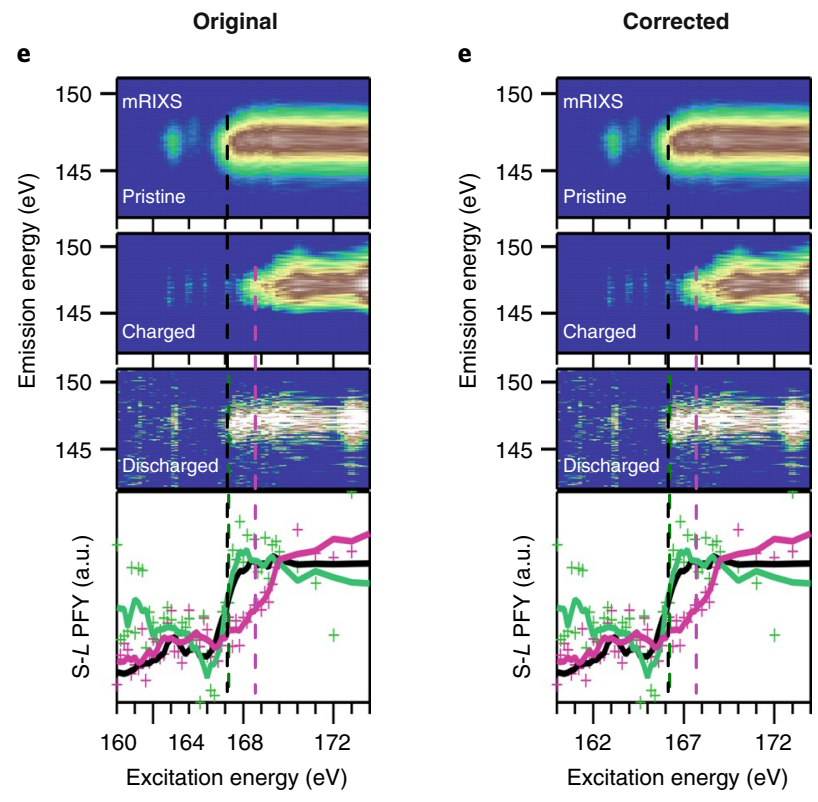

Fig. 5 | Original and Corrected.

Published online: 17 December 2019

https://doi.org/10.1038/s41560-019-0533-9

๑ The Author(s), under exclusive licence to Springer Nature Limited 2019 